Supporting Information

\title{
Surfactant Removal for Colloidal Nanocrystal Catalysts Mediated by N-Heterocyclic Carbene
}

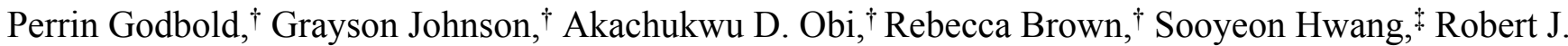
Gilliard, Jr.,,+ Sen Zhang ${ }^{*}, \dagger$

$\dagger$ Department of Chemistry, University of Virginia, Charlottesville, Virginia 22904, United States;

$\$$ Center for Functional Nanomaterials, Brookhaven National Laboratory, Upton, New York 11973, United States.

*To whom correspondence should be addressed. Email: rjg8s@virginia.edu; sz3t@,virginia.edu

This file includes:

Experimental

Table S1

Figure S1 to S15

References 


\section{Experimental}

Materials. Platinum acetylacetonate $\left(\mathrm{Pt}(\mathrm{acac})_{2}, 95 \%\right)$, oleylamine (OAm, 70\%), oleic acid (OAc, 90\%), and Nafion (5wt\% in water) were obtained from Sigma Aldrich. Palladium acetylacetonate $(35 \% \mathrm{Pd}$, $\left.\mathrm{Pd}(\mathrm{acac})_{2}\right)$, Tetrachloroauric acid tetrahydrate $\left(\mathrm{HAuCl}_{4}\right.$, ACS grade), benzyl ether (BE, 90\%), and boranetert-butylamine complex (TBAB, 95\%) were obtained from Acros Organics. Tri-n-octylphosphine (TOP, 90\%) and hydrazine monhydrate were obtained from Alpha Aesar. Glacial acetic acid (AA) was purchased from Fisher Chemical. Vulcan XC 72R carbon was obtained from Fuel Cell Store. These chemicals were used without further purification. 1,3-diisopropyl-4,5-dimethylimidazole-2-ylidene was prepared according to literature ${ }^{1}$ and recrystallized from hexanes before use. Solvents of acetone, ethanol, isopropanl, acetonitrile, and hexanes were of $99 \%$ assay or greater purity and were purchased from Fisher Chemical. Isopropanol and hexanes were refluxed over magnesium and metallic sodium, respectively, under a $\mathrm{N}_{2}$ flow and used in the glovebox. All syntheses were performed using standard Schlenk techniques.

Synthesis of Pt nanocrystals. $300 \mathrm{mg}$ of $\mathrm{Pt}(\mathrm{acac})_{2}, 30 \mathrm{ml}$ of BE, $2.5 \mathrm{ml}$ of OAm, and $4.75 \mathrm{ml}$ of OAc were put into a four neck reaction flask. The mixture was magnetically stirred and degassed under vacuum at room temperature before injection of $1 \mathrm{ml}$ of TOP under $\mathrm{N}_{2}$. The solution was then degassed at $100{ }^{\circ} \mathrm{C}$ for 1 hour before rapid heating $\left(\sim 40^{\circ} \mathrm{C} / \mathrm{min}\right)$ to $300^{\circ} \mathrm{C}$. This temperature was held for 15 minutes before the solution was allowed to cool. The nanocrystals were collected by adding ethanol as an anti-solvent and centrifugation (8000 rpm, 10 minutes). The supernatant was decanted and product further purified with hexanes and ethanol.

Synthesis of Pd nanocrystals. $100 \mathrm{mg}$ of $\mathrm{Pd}(\mathrm{acac})_{2}$ and $12 \mathrm{ml}$ of OAm were added to a four neck reaction flask. The mixture was magnetically stirred and degassed under vacuum at $60{ }^{\circ} \mathrm{C}$ for 1 hour. Under $\mathrm{N}_{2}, 200$ $\mathrm{mg}$ of TBAB dissolved in $3 \mathrm{ml}$ of OAm was added into the solution. The solution was allowed to react for 30 minutes. The nanocrystals were collected by adding ethanol as an anti-solvent and centrifugation (8000 $\mathrm{rpm}, 10$ minutes), and were further washed and purified with ethanol and hexanes. Because these nanocrystals were surface bound with OAm post synthesis, once redispersed in hexanes post purification, $1 \mathrm{ml}$ of TOP was added and stirred for 4 hours before an additional two purifications via ethanol, hexanes, and centrifugation.

Synthesis of Au nanocrystals. $200 \mathrm{mg}$ of $\mathrm{HAuCl}_{4}$ was dispersed in $1.7 \mathrm{ml}$ of OAm, $3.2 \mathrm{ml}$ of OAc and 3 $\mathrm{mL}$ of hexane by shaking and sonication. To this, $20 \mathrm{ml} \mathrm{BE}$ was added and degassed at room temperature for 30 minutes in a four neck reaction flask. Next, $0.6 \mathrm{ml}$ of TOP was introduced and further degassed at $90{ }^{\circ} \mathrm{C}$ for 1 hour before the addition of $160 \mathrm{mg}$ of TBAB under $\mathrm{N}_{2}$. The reaction was allowed to run for 30 minutes. The nanocrystals were collected by addition of ethanol as an anti-solvent and centrifugation (8000 rpm, 10 minutes), and were washed and purified with ethanol and hexane.

Structure Characterization. Transmission electron microscopy (TEM) images were obtained on a FEI Tecnai Spirit (120 kV). Scanning TEM (STEM) analyses were carried out using a Hitachi HD2700C (200 $\mathrm{kV}$ ) equipped with a probe aberration-corrector and an electron energy loss spectroscopy (EELS) detector in the Center for Functional Nanomaterials at Brookhaven National Laboratory. The 2D EELS elemental mappings were collected using a high resolution Gatan-Enfina ER with a probe size of $1.3 \AA$. A power law function was used for EELS background subtraction. Inductively coupled plasma optical emission spectrometry (ICP-OES) analyses were conducted on a PerkinElmer Avio-200 ICP optical emission spectrometer to determine the metal loading on all supported catalysts. X-ray photoelectron spectroscopy (XPS) was carried out using PHI VersaProbe III which is equipped with monochromatic Al K-alpha Xrays $(1486.6 \mathrm{eV})$ and spherical capacitor energy analyzer to identify the surface composition and electronic structure differences before and after NHC cleaning. Survey spectra were measured with a $100 \mu \mathrm{m} \mathrm{X-ray}$ beam spot and $224 \mathrm{eV}$ pass energy. Spectra were also measured with a $100 \mu \mathrm{m}$ spot size but with a $26 \mathrm{eV}$ pass energy for improved energy resolution. Data were analyzed in PHI Multipak 9.8.0.19, where a Shirley background was subtracted to remove the inelastic component. The binding energy scale was charge referenced to the $\mathrm{C} 1 \mathrm{~s}$ peak of graphitic carbon at $284.5 \mathrm{eV}$. Diffuse reflectance infrared Fourier-transform 
spectroscopy (DRIFTS) was carried out to indicate organic surface molecules on a Nicolet iS 50 FT-IR (Thermo Scientific, USA) equipped with a DiffusIR diffuse reflectance cell (Pike Technologies). After the sample was loaded into a sliding two sample mount with a reference containing the same solvent, it was purged with $\mathrm{N}_{2}$ at room temperature until no loss from the solvent reference was seen. Next, the background was collected before sliding the sample into beam path for sample collection. Kubelka-Munk corrections was used and scalar adjustments were made as sample concentrations varied. This is denoted in the figures below by KM units (a.u).

Preparation of Electrocatalysts. The TOP-bound nanocrystals were mixed, approximately 1:4 in weight, with Vulcan-72 carbon in hexanes and sonicated for 1 hour before collection via addition of isopropanol and centrifugation. (Exact metal loading was determined with ICP-OES). Next, the ligand exchange or annealing treatments (see below) to clean the nanocrystal surface were performed. After treatment, all samples were vacuum dried. An electrochemical ink $(2 \mathrm{mg} / \mathrm{mL})$ was prepared with $\mathrm{EtOH}$ and $10 \mathrm{wt} \%$ Nafion. The ink was drop cast $(\sim 10-20 \mu \mathrm{L})$ onto a glassy carbon electrode $(5 \mathrm{~mm}$ in diameter) and allowed to dry in ambient conditions for electrochemical testing.

Untreated: An untreated sample had no additional steps performed on it after being loaded onto Vulcan-72 carbon.

Hydrazine wash: The sample was dispersed in $20 \mathrm{ml}$ of ethanol before the addition of $1 \mathrm{ml}$ of hydrazine. The mixture was kept strirring overnight (12 hours). Two purification steps with ethanol and centrifugation followed to remove any residual hydrazine.

Acetic acid wash: The sample was dispersed in glacial acetic acid and heated to $60{ }^{\circ} \mathrm{C}$ under $\mathrm{N}_{2}$ with magnetic stirring overnight (12 hours). Three wash steps were then performed with ethanol.

Annealed in Air: The sample annealed in air was placed in a ceramic crucible and heated in a muffle oven for 4 hours at $300{ }^{\circ} \mathrm{C}$.

NHC wash: A full NHC wash involved the addition in a glovebox of a solution NHC/hexanes to each sample so that the NHC added was 2-3 times the mass of the metal. This mixture was stirred for four hours before collection via centrifugation. To remove the surface bound NHC, glacial acetic acid was added and stirred for 1 hour before purification and collection via centrifugation. Supported materials could be washed with ethanol or isopropanol. Unsupported materials were best redistibuted with THF and crashed out with hexanes.

Electrochemical Analyses. The GEOR measurements were performed on a Biologic VMP3 potentiostat with a three-electrode system consisting of a glassy carbon working electrode $(5 \mathrm{~mm}$ in diameter), a $\mathrm{Hg} / \mathrm{HgO}$ reference elctrode $(1.0 \mathrm{M} \mathrm{KOH})$, and a Pt plate counter electrode. The $\mathrm{Hg} / \mathrm{HgO}(1.0 \mathrm{M} \mathrm{KOH})$ electrode was calibrated vs. reversible hydrogen electrode (RHE) by the open circuit voltage test prior to electrocatalysis. The $\mathrm{N}_{2}$-saturated $1 \mathrm{M} \mathrm{KOH}$ was used as the electrolyte. CVs were conducted in the range from 0.02 to $1.3 \mathrm{~V}$ ( $v s$. RHE) at a scan rate of $50 \mathrm{mV} / \mathrm{s}$. LSVs were performed in an $\mathrm{N}_{2}$-saturated $1 \mathrm{M} \mathrm{KOH}$ containing glycerol (concentration: $1 \mathrm{M}$ ) by sweeping from 0.02 to $1.3-1.5 \mathrm{~V}$ (vs. RHE) at $1 \mathrm{mV} / \mathrm{s}$. The $\mathrm{CO}_{2} \mathrm{RR}$ electrochemical analyses were performed in a H-type cell with a Nafion-212 membrane assembled between the cathode and anode compartments. Each chamber was filled with $12 \mathrm{ml}$ of $0.1 \mathrm{M} \mathrm{KHCO} 3$ electrolyte. To assess the product distribution, controlled potential electrolyses (CPE) were performed at selected potentials. Before electrocatalysis the cathode chamber was purged for 20 minutes with $100 \mathrm{sccm} \mathrm{CO}_{2}$. During the electrolysis, $\mathrm{CO}_{2}$ was steadily supplied to the cathode compartment at a rate of $10 \mathrm{sccm}$, and the gas phase effluent in the headspace of the cathode compartment was continuously introduced to the sampling loop of a Shimadzu gas chromatograph (GC2014). The gaseous product stream was analysed at intervals by a thermal conductivity detector (TCD) and a flame ionization detector (FID) equipped with a methanizer, using argon as the carrier gas. 
Table S1. Pt 4f XPS fitting of different carbon-supported Pt samples.

\begin{tabular}{ccccc}
\hline Sample & $\begin{array}{c}\mathbf{4 f}_{7 / 2} \text { Peak Position } \\
(\mathbf{e V})\end{array}$ & $\begin{array}{c}\mathbf{4 f}_{7 / 2} \mathbf{F W H M} \\
(\mathbf{e V})\end{array}$ & $\begin{array}{c}\mathbf{4 f}_{5 / 2} \text { Peak Position } \\
(\mathbf{e V})\end{array}$ & $\begin{array}{c}\mathbf{4 f}_{\mathbf{5} / \mathbf{2}} \mathbf{F W H M} \\
(\mathbf{e V})\end{array}$ \\
\hline Pt-TOP Untreated & $71.5 \mathrm{eV}$ & $1.44 \mathrm{eV}$ & $74.8 \mathrm{eV}$ & $1.49 \mathrm{eV}$ \\
\hline $\begin{array}{c}\text { Pt-TOP acetic acid } \\
\text { washed }\end{array}$ & $71.5 \mathrm{eV}$ & $1.50 \mathrm{eV}$ & $74.8 \mathrm{eV}$ & $1.53 \mathrm{eV}$ \\
\hline $\begin{array}{c}\text { NHC-washed Pt } \\
\text { (before protonation) }\end{array}$ & $71.5 \mathrm{eV}$ & $1.57 \mathrm{eV}$ & $74.8 \mathrm{eV}$ & $1.63 \mathrm{eV}$ \\
\hline $\begin{array}{c}\text { NHC-washed Pt } \\
\text { (after protonation) }\end{array}$ & $71.5 \mathrm{eV}$ & $1.33 \mathrm{eV}$ & $74.8 \mathrm{eV}$ & $1.34 \mathrm{eV}$ \\
\hline
\end{tabular}
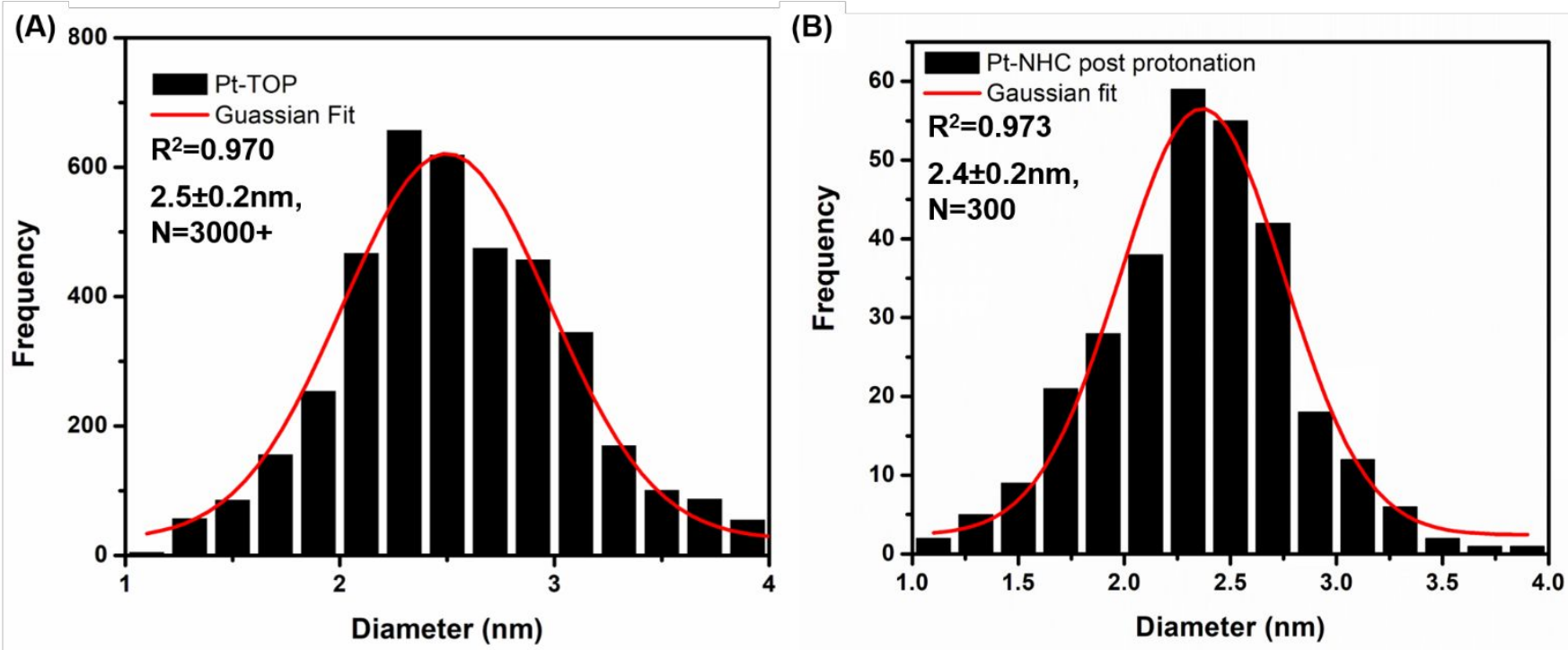

Figure S1. Histograms with Gaussian fits of the nanocrystal size distribution of (A) as-synthesized Pt-TOP sample (account number $\mathrm{N}>3000$ ) and (B) NHC-treated Pt after protonation sample (N=300). Pt-TOP and Pt-NHC post protonation samples have an average size of 2.4 and $2.3 \mathrm{~nm}$, respectively. Size analysis was conducted using automatic function in ImageJ for Pt-TOP sample, while manual calculation was used for Pt-NHC post protonation sample due to carbon background interference. 

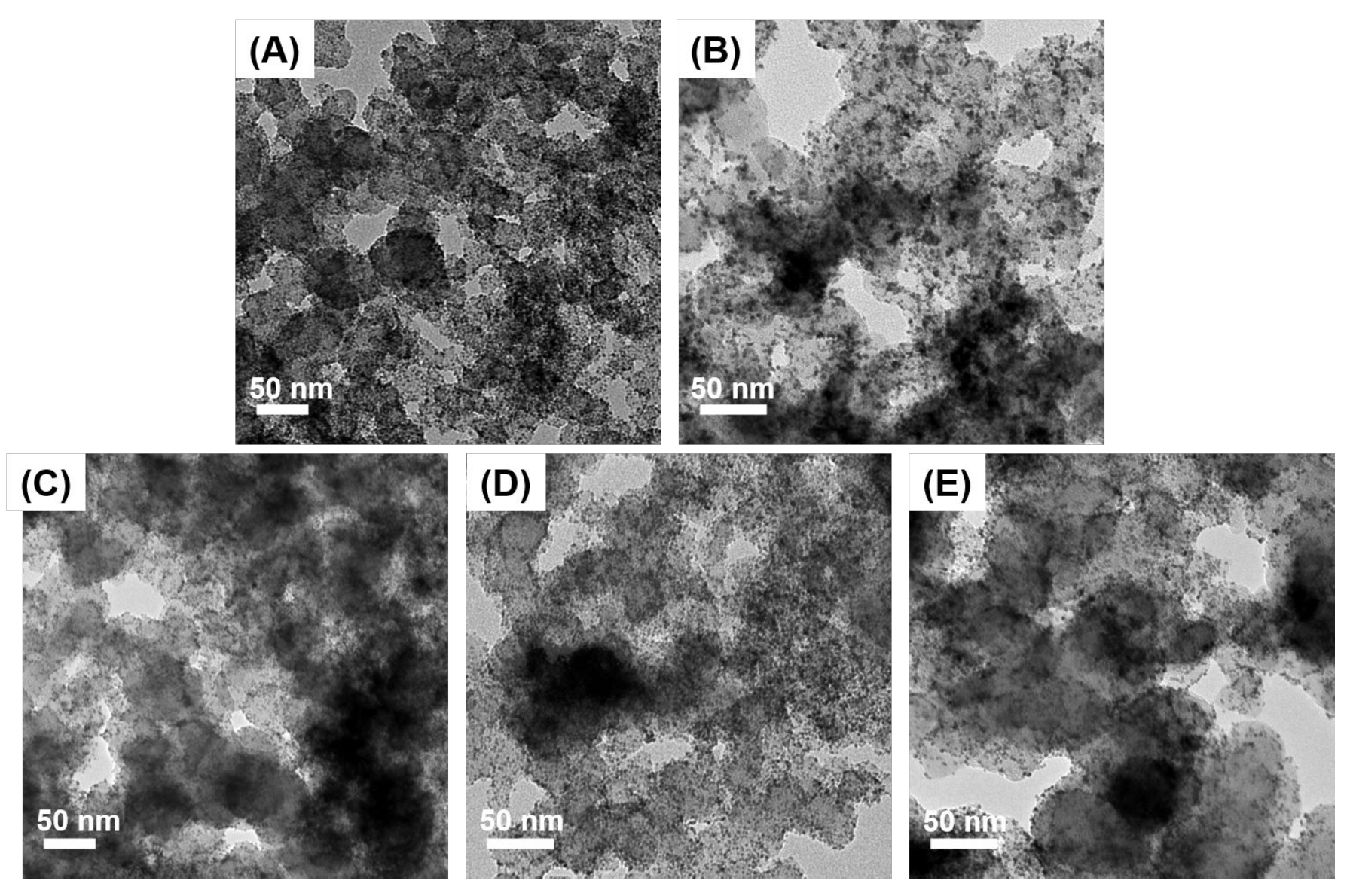

Figure S2. TEM images of different carbon-supported Pt samples. (A) untreated, (B) annealed in air, (C) hydrazine-washed sample, (D) acetic acid-washed sample, and (E) NHC washed sample (without protonation).

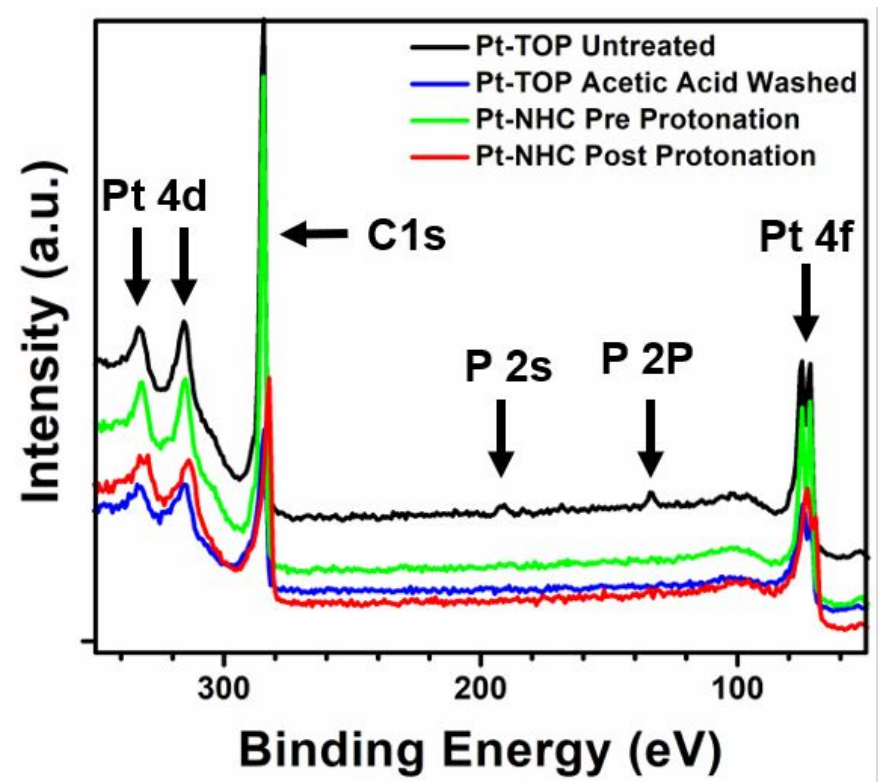

Figure S3. XPS survey spectra of carbon-supported Pt samples with various treatments. Only the untreated sample shows weak P signal. 


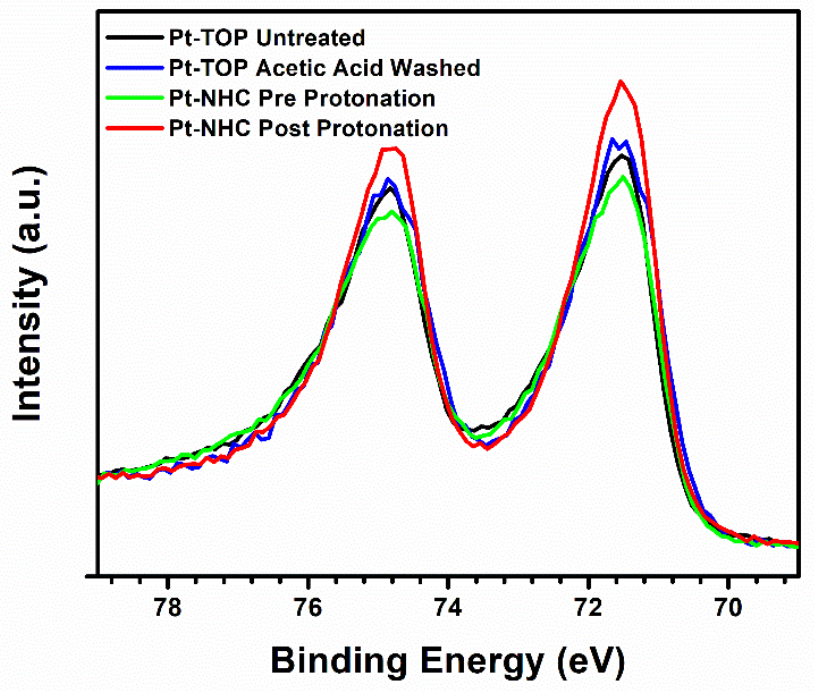

Figure S4. High resolution Pt 4f XPS spectra of carbon-supported Pt samples. Peak specifications data is displayed in Table S1.
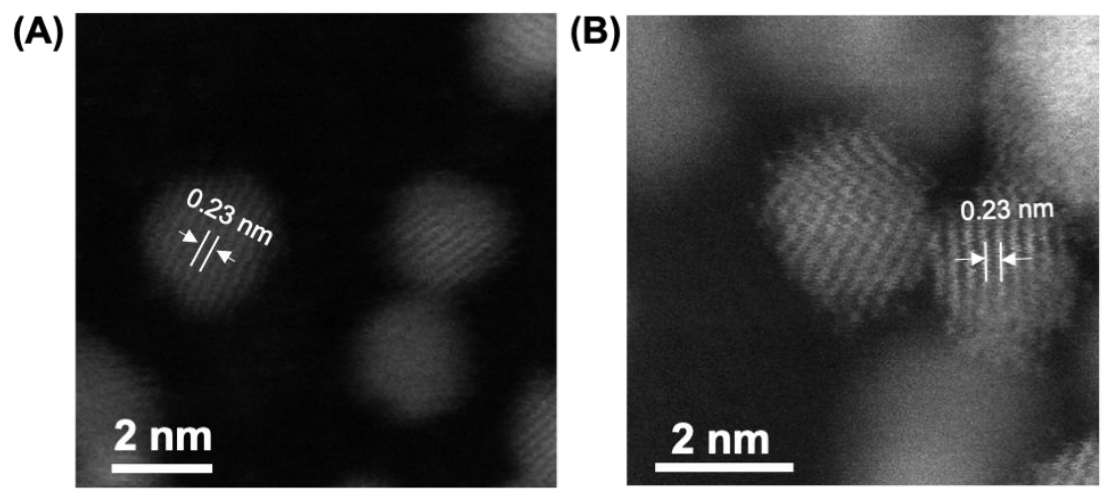

Figure S5. HR STEM images of (A) as -synthesized Pt-TOP and (B) Pt-NHC post protonation. (111) planes of $f c c$-Pt were indexed in both images. 


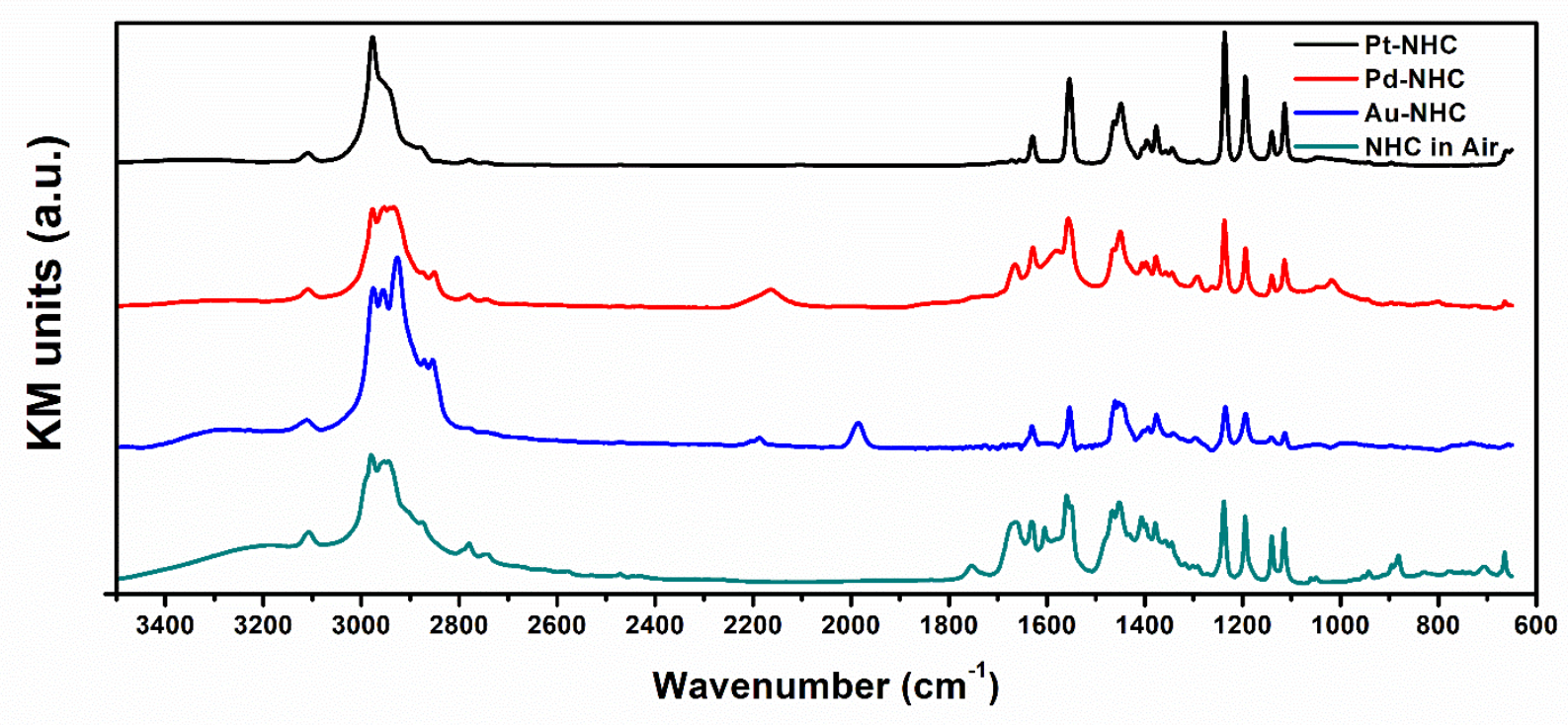

Figure S6. DRIFTs spectra of NHC and NHC-bound nanocrystals in air. All spectra show generally good agreement, indicating the major bounding and electronic motifs are similar. Variance between similar modes across NHC-bound nanocrystals could be caused by the electronic coupling between NHC and nanocrystals. Appearance of extra modes in Au and Pd samples could be a result of reactions with NHC ring.

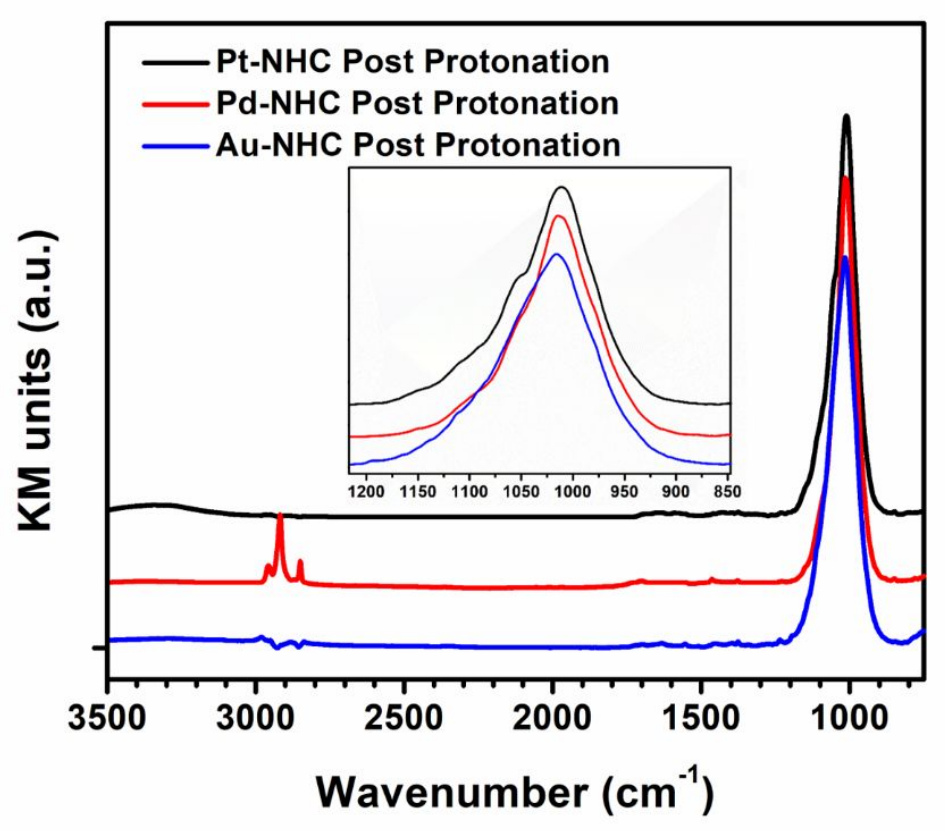

Figure S7. DRIFTs spectra of NHC-washed Pt, Pd and Au colloidal nanocrystals after protonation. The Pt and $\mathrm{Au}$ sample spectra show no signs of organics, indicating surfaces bare of any organics. Pd surface shows minisucle amount of TOP as idicated by characteristic $\mathrm{C}-\mathrm{H}$ stretching $\left(3000 \mathrm{~cm}^{-1}\right)$ and $\mathrm{C}-\mathrm{H}$ bending $\left(\delta\left(\mathrm{CH}_{2}\right)\right.$ and $\delta_{\mathrm{s}}\left(\mathrm{CH}_{3}\right)$ at 1463 and $\left.1377 \mathrm{~cm}^{-1}\right){ }^{2}$ The intense and broad modes around $1000 \mathrm{~cm}^{-1}$ (inset shows zoom-in view) are attributed to various surface-oxide (M-O) stretches. ${ }^{3-6}$ 


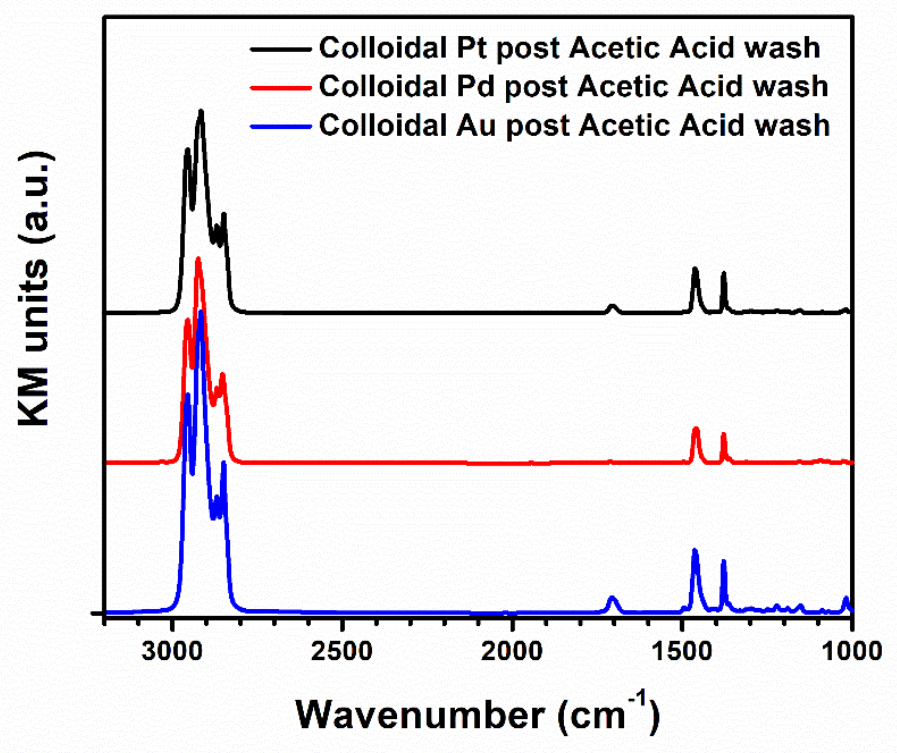

Figure S8. DRIFTS spectra of colloidal nanocrystals washed with two consecutive glacial acetic acid treatments at $60{ }^{\circ} \mathrm{C}$. TOP clearly remains on the surface as demonstrated by the characteristic $\mathrm{C}-\mathrm{H}$ stretching $\left(3000 \mathrm{~cm}^{-1}\right)$ and $\mathrm{C}-\mathrm{H}$ bending $\left(\delta\left(\mathrm{CH}_{2}\right)\right.$ and $\delta_{\mathrm{s}}\left(\mathrm{CH}_{3}\right)$ at 1463 and $\left.1377 \mathrm{~cm}^{-1}\right)$. Some acetic acid residual remains as indicated by additional $\mathrm{C}=\mathrm{O}$ stretching around $1750 \mathrm{~cm}^{-1}$.

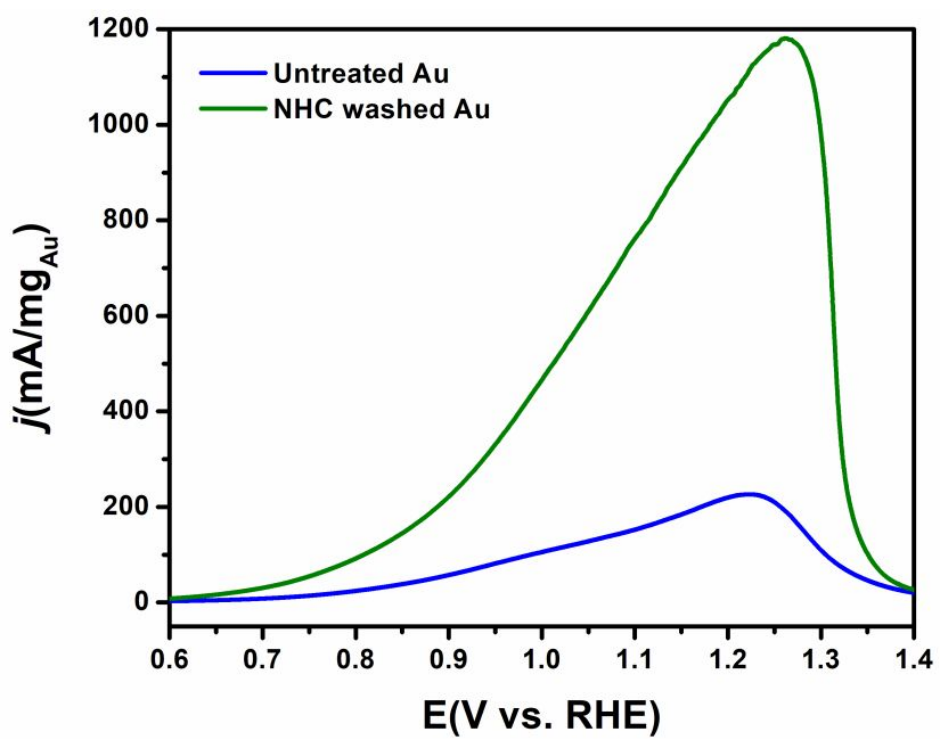

Figure S9. LSVs carbon-supported Au catalysts for the GEOR in 1M KOH containing $1 \mathrm{M}$ glycerol. 


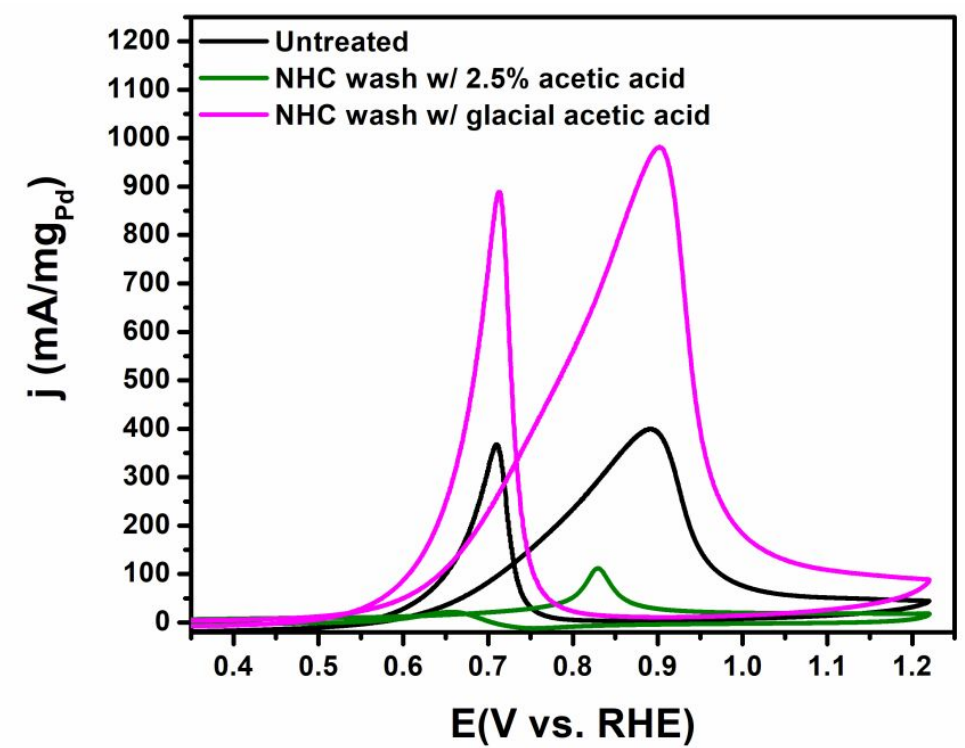

Figure S10. CVs of carbon-supported Pd catalysts (scan rate: $50 \mathrm{mV} \mathrm{sec}^{-1}$, in $1 \mathrm{M} \mathrm{KOH}$ containing $1 \mathrm{M}$ glycerol) showing the dilute acetic acid cannot effectively remove NHC bound with nanocrystals.
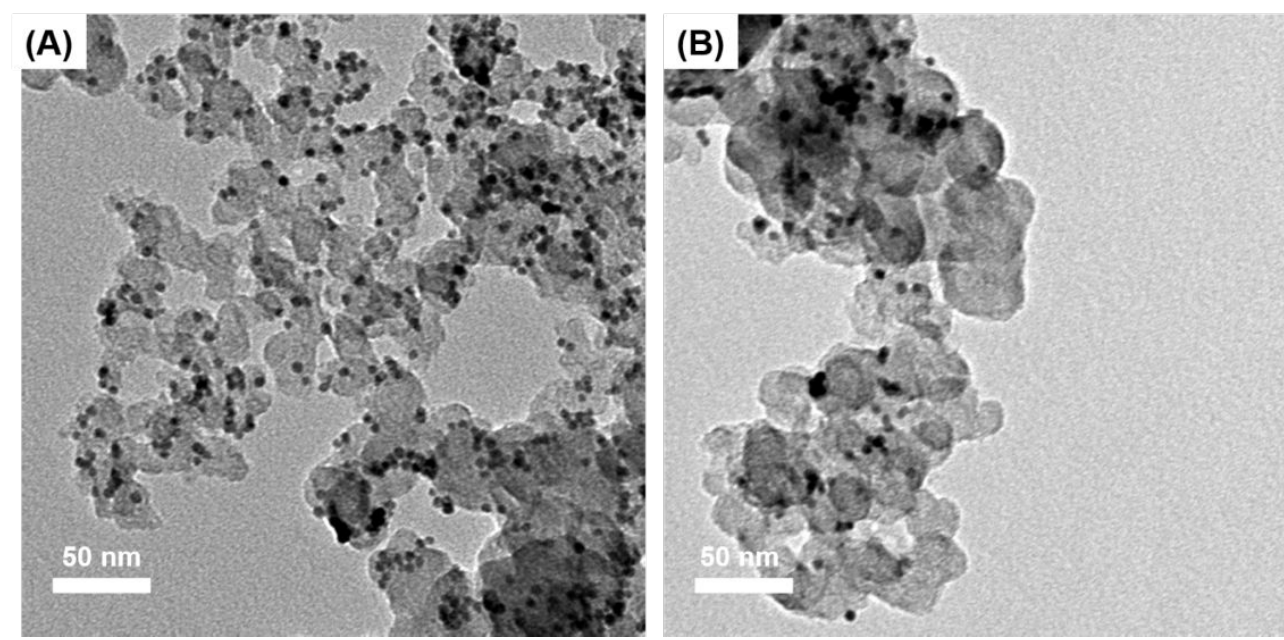

Figure S11. TEM images of carbon-supported Pd catalysts before (A) and after (B) GEOR tests. The catalyst was treated with the present NHC-mediated cleaning method. 

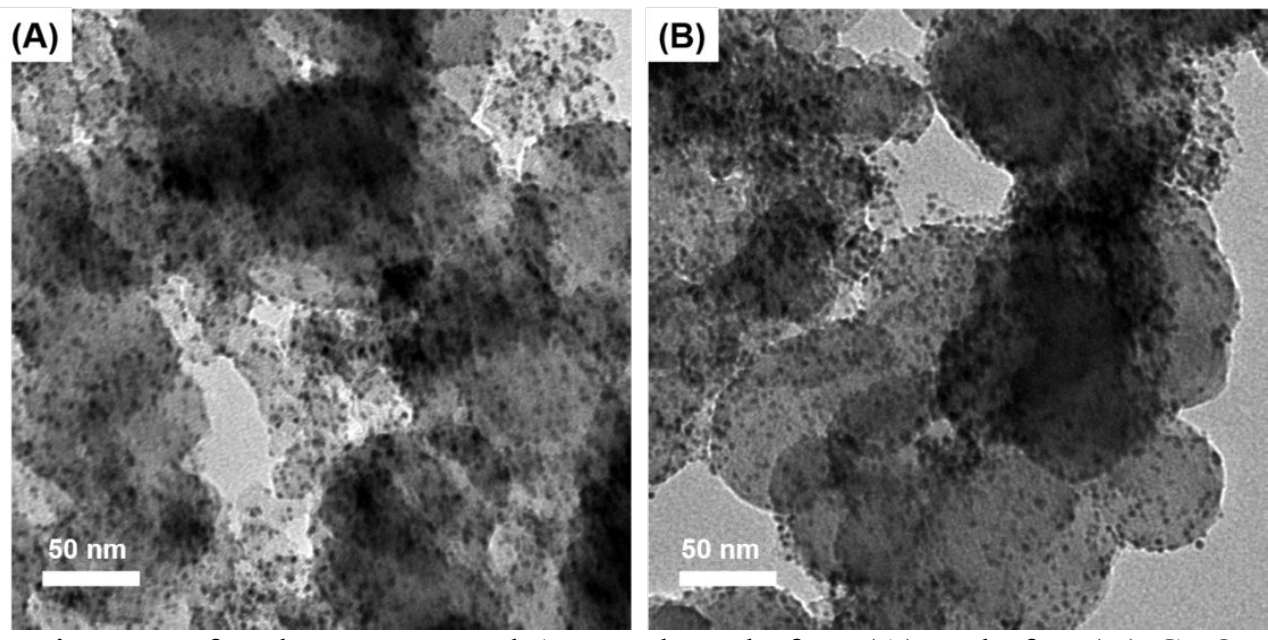

Figure S12. TEM images of carbon-supported Au catalysts before (A) and after (B) GEOR tests. The catalyst was treated with the present NHC-mediated cleaning method.
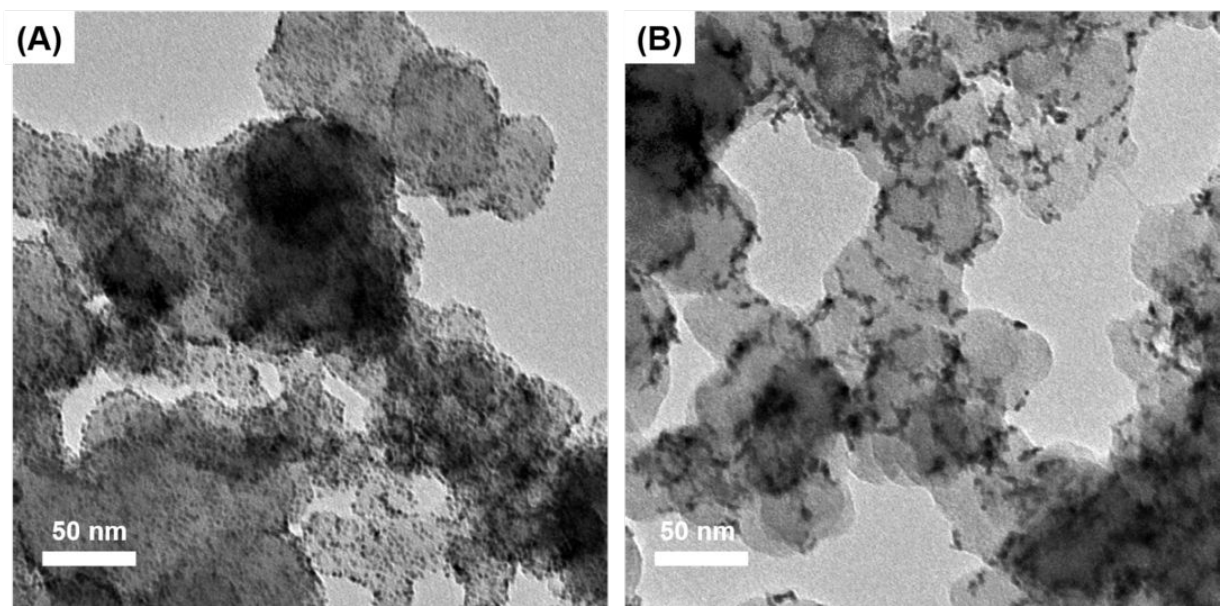

Figure S13. TEM images of carbon-supported Pt catalysts before (A) and after (B) GEOR tests. The catalyst was treated with the present NHC-mediated cleaning method.
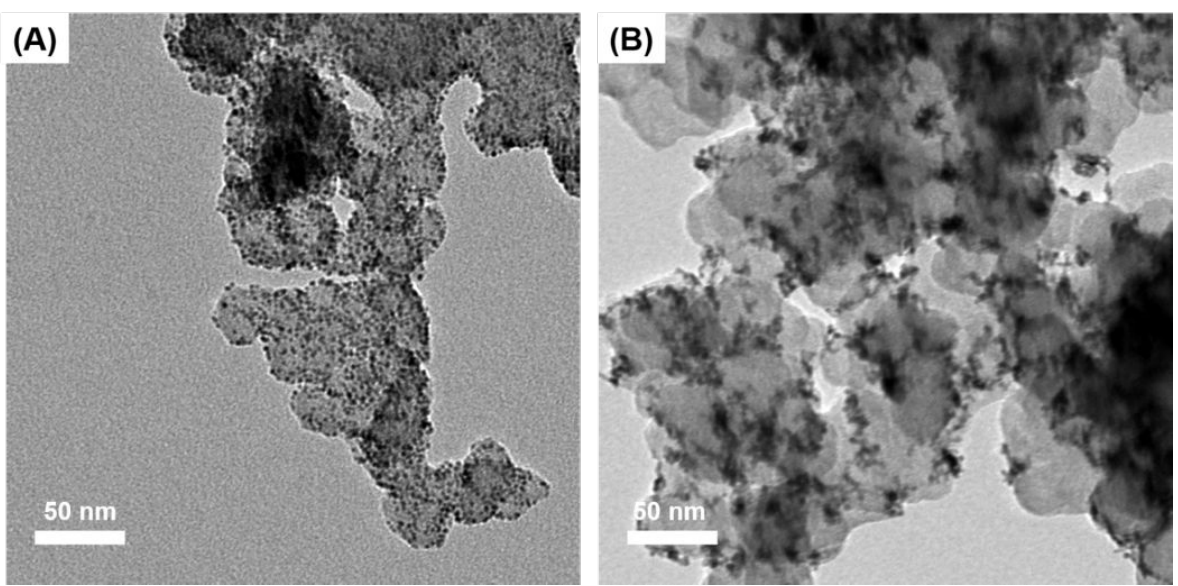

Figure S14. TEM images of carbon-supported Pt catalysts before (A) and after (B) GEOR tests. The catalyst was untreated and has a TOP-bound surface. 


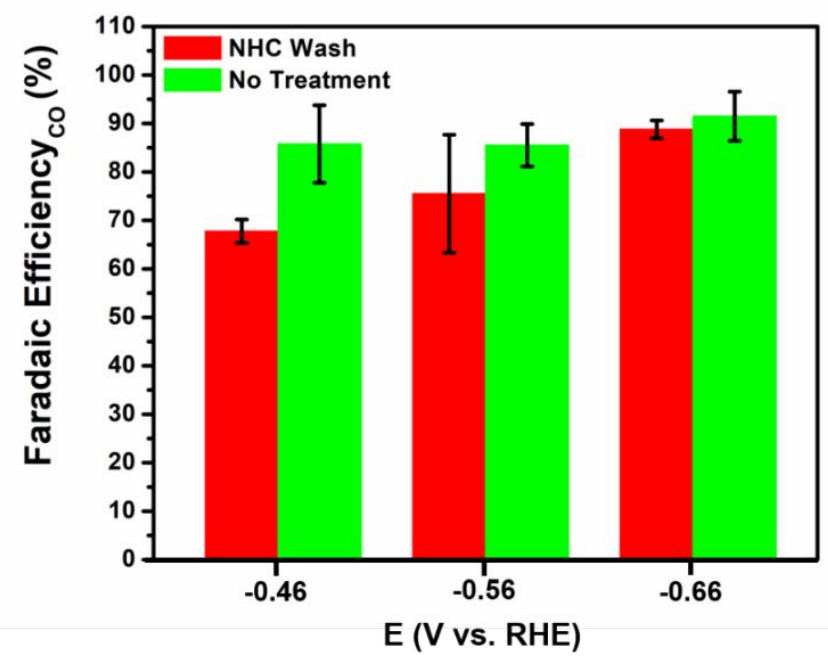

Figure S15. Faradaic efficiencies toward $\mathrm{CO}$ product in $\mathrm{CO}_{2} \mathrm{RR}$ using untreated and NHC-treated Au catalyst (after protonation). Error bars represent the standard deviation of the FEs toward CO product determined from three independent samples.

\section{References}

1. Kuhn, N.; Kratz, T., Synthesis of Imidazol-2-ylidenes by Reduction of Imidazole-2(3H)-thiones. Synthesis 1993, 1993 (06), 561-562.

2. Young, A. G.; Al-Salim, N.; Green, D. P.; McQuillan, A. J., Attenuated Total Reflection Infrared Studies of Oleate and Trioctylphosphine Oxide Ligand Adsorption and Exchange Reactions on CdS Quantum Dot Films. Langmuir 2008, 24 (8), 38413849 .

3. Sugimura, F.; Sakai, N.; Nakamura, T.; Nakamura, M.; Ikeda, K.; Sakai, T.; Hoshi, N., In situ observation of Pt oxides on the low index planes of Pt using surface enhanced Raman spectroscopy. Physical Chemistry Chemical Physics 2017, 19 (40), 27570-27579.

4. Tanaka, H.; Sugawara, S.; Shinohara, K.; Ueno, T.; Suzuki, S.; Hoshi, N.; Nakamura, M., Infrared Reflection Absorption Spectroscopy of OH Adsorption on the Low Index Planes of Pt. Electrocatalysis 2015, 6 (3), $295-299$.

5. Seitsonen, A. P.; Zhu, Y.; Bedürftig, K.; Over, H., Bonding Mechanism and Atomic Geometry of an Ordered Hydroxyl Overlayer on $\operatorname{Pt}(111)$. Journal of the American Chemical Society 2001, 123 (30), 7347-7351.

6. Ueno, T.; Tanaka, H.; Sugawara, S.; Shinohara, K.; Ohma, A.; Hoshi, N.; Nakamura, M., Infrared spectroscopy of adsorbed $\mathrm{OH}$ on $\mathrm{n}(111)-(100)$ and $\mathrm{n}(111)-(111)$ series of Pt electrode. J Electroanal Chem 2017, 800, 162-166. 